\title{
ChemComm
}

\section{Rhodium-catalyzed intermolecular C-H amination of simple hydrocarbons using the shelf-stable nonafluorobutanesulfonyl azide $\dagger$}

Cite this: Chem. Commun., 2
49, 9194
Received 19th June 2013,
Accepted 11th August 2013

DOI: $10.1039 /$ c3cc44594a

www.rsc.org/chemcomm

A new procedure has been developed for the direct intermolecular C-H amination of simple hydrocarbons using shelf-stable nonafluorobutanesulfonyl azide in the presence of a dirhodium(II) tetracarboxylate catalyst under mild reaction conditions. Some mechanistic details are briefly discussed on the basis of control experiments.

The direct chemoselective transformation of unactivated $\mathrm{sp}^{3}$ hybridized $\mathrm{C}-\mathrm{H}$ bonds into $\mathrm{C}-\mathrm{N}$ bonds has emerged as a powerful tool in organic chemistry and the chemical industry that can streamline chemical synthesis by saving functional group transformations (such as hydroxyl to amine) and protection-deprotection steps. ${ }^{1}$ Typical aminating reagents used for this purpose are high-energy species bearing electron-deficient $\mathrm{N}$-substituents and capable of generating multiple bonds between late transition metals and nitrogen, such as iminoiodinanes (often prepared in situ), $N$-haloamines, and azides. Intra- and intermolecular protocols have been described based on $\mathrm{Mn},{ }^{2} \mathrm{Fe},{ }^{2 c, 3} \mathrm{Ru}^{2 b, 4} \mathrm{Co},{ }^{2 c, 5} \mathrm{Rh}^{3 a, 6}$ $\mathrm{Ir}^{4 b, 7} \mathrm{Ni}^{2 c}{ }^{2 c} \mathrm{Pd},{ }^{8} \mathrm{Cu},{ }^{1 c, 9} \mathrm{Ag},{ }^{10} \mathrm{Au},{ }^{11}$ and $\mathrm{Zn}^{12}$ catalysts, including asymmetric versions, ${ }^{2 b, 4 b, 6 d, f, 7}$ as well as under metal-free ${ }^{13,14}$ conditions. In most of these transformations the reactive species is believed to be a (metal-)nitrene intermediate, which regioselectively inserts into the most electron-rich $\mathrm{C}-\mathrm{H}$ bond unless steric factors contravene.

The use of azides is particularly appealing in this context since the reaction is highly atom-efficient and environmentally friendly, producing only gaseous nitrogen as a by-product and not requiring the addition of an oxidant. Polyfluoroalkanesulfonyl azides are the most electrophilic among organic azides, but have been very scarcely used in amination reactions ${ }^{13 e, 15}$ probably due to the highly hazardous nature of their simplest and most typically employed representative, triflyl azide $\left(\mathrm{TfN}_{3}\right) \cdot{ }^{16}$ However, it has been recently shown that the higher molecular weight analog nonafluorobutanesulfonyl azide $\left(\mathrm{NfN}_{3}\right)$ is a more efficient, shelf-stable and economic reagent in diazo-transfer reactions ${ }^{17}$ and other useful

Instituto de Química Orgánica General, CSIC, Juan de la Cierva 3, 28006 Madrid, Spain. E-mail: jl.chiara@csic.es; Fax: +34-915644853; Tel: +34-915622900

$\dagger$ Electronic supplementary information (ESI) available: Detailed experimental procedures and copies of ${ }^{1} \mathrm{H},{ }^{19} \mathrm{~F}$, and ${ }^{13} \mathrm{C}$ NMR spectra. See DOI: 10.1039/c3cc44594a transformation mediated by $\operatorname{TfN}_{3} \cdot{ }^{17 f, 18}$ In connection with our recent studies on new synthetic applications of $\mathrm{NfN}_{3},{ }^{17 b-d, f}$ here we describe how this reagent can perform the $\mathrm{C}-\mathrm{H}$ amination of simple hydrocarbons under mild thermal conditions in the presence of a metal catalyst.

We selected indane as a model substrate for an initial screening of reaction conditions using 1.2 equivalents of $\mathrm{NfN}_{3}$ (Table 1). No reaction occurred under simple thermal conditions in 1,2-dichloroethane (DCE) at $90-110{ }^{\circ} \mathrm{C}$ (below the reported decomposition temperature of $\mathrm{NfN}_{3}$ of $\left.c a .120{ }^{\circ} \mathrm{C}\right)^{13 e}$ for 12 hours in the absence of a metal catalyst (entry 1). After testing several transition metal salts (5 mol\%) (entries 2-5), we found that dirhodium(II) tetracarboxylates promoted the reaction smoothly to afford the nonafluorobutanesulfonamide 1 in good isolated yields (entries 6, 12 and 13). The amination took place exclusively at the benzylic carbon. Only a marginal improvement in product yield was obtained with the more active $\mathrm{Rh}_{2}(\mathrm{esp})_{2}$ catalyst (entry 13). ${ }^{6 c} \mathrm{~A}$ decrease in the reaction temperature had a dramatic deleterious effect, the reaction becoming sluggish below $70{ }^{\circ} \mathrm{C}$ (entries 7 and 8). Catalyst loadings as low as $1 \mathrm{~mol} \%$ could be employed at the expense of a reduced,

Table 1 Development of the intermolecular sulfamidation reaction

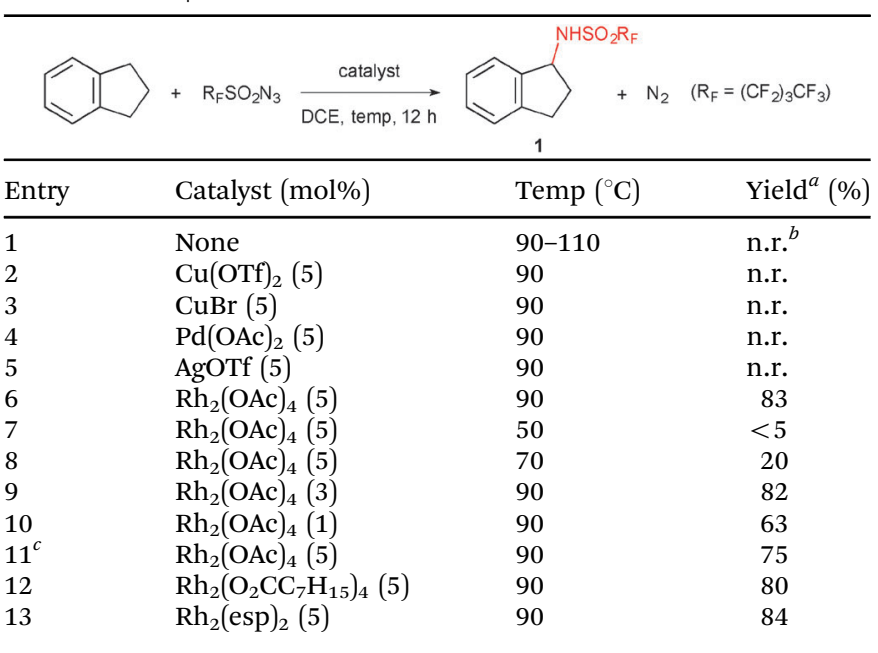

${ }^{a}$ Isolated yield. ${ }^{b}$ No reaction. ${ }^{c}$ Two equivalents of $\mathrm{NfN}_{3}$ were used. 
but still synthetically useful, amination yield (entry 10). Use of an excess of $\mathrm{NfN}_{3}$ (2 equivalents) resulted in a slightly reduced product yield without formation of polyaminated products or imine ${ }^{5 a, 9 c}$ (entry 11). Optimum results were obtained at $90{ }^{\circ} \mathrm{C}$ employing a 3-5 mol\% of catalyst and 1.2 equivalents of $\mathrm{NfN}_{3}$ (entries 6, 9, 12 and 13).

We next examined the substrate scope under the cost-efficient optimized conditions using $5 \mathrm{~mol} \% \mathrm{Rh}_{2}(\mathrm{OAc})_{4}$ at $90{ }^{\circ} \mathrm{C}$ in DCE. Simple aromatic compounds bearing primary, secondary or tertiary benzylic hydrogens where regioselectively monosulfamidated at the benzylic position with moderate to good isolated yields (47-80\%) (Scheme 1). Amination of the aromatic ring was never observed under the employed experimental conditions. ${ }^{13 a, 15 a, 19}$ In the case of isochromane, the reaction occurred exclusively at the ethereal benzylic carbon (compound 3). However, in contrast to related $\mathrm{Rh}$ (II)-catalyzed amination reactions of aliphatic $\mathrm{C}-\mathrm{H}$ bonds with aryl azides, ${ }^{6 i}$ no reaction was observed for substrates bearing carbonyl, ester, carbamoyl or sulfonamido groups, the starting compound being recovered unchanged after heating at $90{ }^{\circ} \mathrm{C}$ for $16 \mathrm{~h}$ (Scheme 1, last row).

Encouraged by these results, we next examined the scope of the transformation on simple hydrocarbon substrates bearing no functional groups (Scheme 2). Moderate to good isolated yields (45-70\%) of monosulfamidated products were obtained under the previous optimized conditions using the hydrocarbons as limiting reagents (14-18) or as solvents (11-13). In the case of adamantane, amination took place regioselectively at the tertiary $\mathrm{C}-\mathrm{H}$ bond, with no product arising from methylene amination being detected in spite of the 3:1 statistical preference for insertion at the methylene $\mathrm{C}-\mathrm{H}$ bonds in this molecule. In contrast, trans-decalin was aminated exclusively at the methylene carbons, yielding an inseparable 2:3 mixture (determined from the ${ }^{1} \mathrm{H}$ NMR of the crude) of two regio- or stereoisomers (15). The larger steric encumbrance of the axially oriented methine hydrogens probably explains this selectivity. Thus, in cis-decalin an inseparable mixture of three regio- and/or stereo-isomeric sulfonamides (16) was formed showing that amination at the now more accessible methine carbon has taken place. The strong signal overlap observed in the ${ }^{1} \mathrm{H}$ NMR of the decalin reaction products impeded their stereochemical assignment. ${ }^{9 f}$ A similar change in $2^{\circ}-3^{\circ}$ site selectivity was observed for cis- and trans-1,4dimethylcyclohexane. While the cis-isomer reacted preferentially

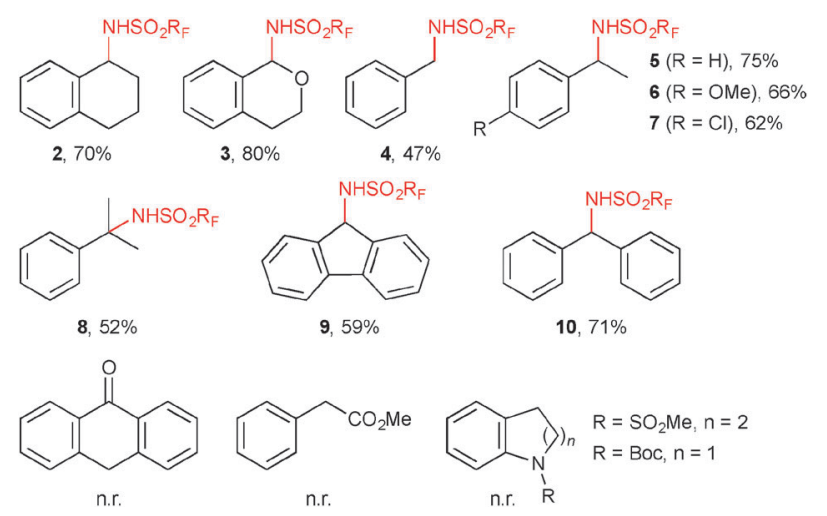

Scheme 1 Intermolecular amination of benzylic $\mathrm{C}-\mathrm{H}$ bonds.

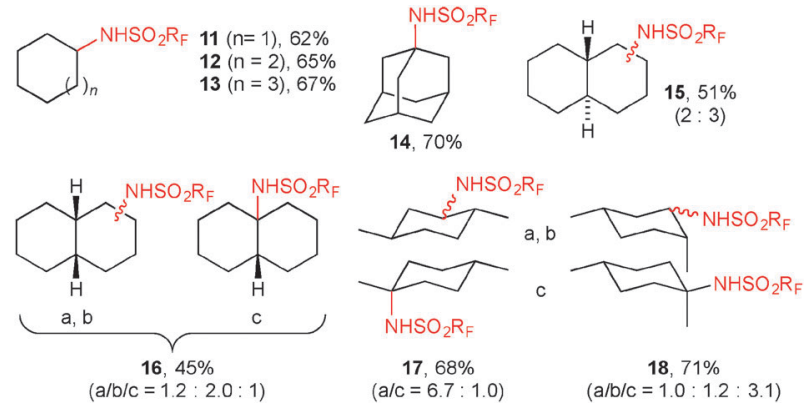

Scheme 2 Intermolecular amination of simple cyclic alkanes.

at the methylene carbons to afford an inseparable 6.7:1 mixture of $2^{\circ}-3^{\circ}$ sulfonamides 17 as single (unassigned) diastereoisomers, the trans-isomer gave a 2.2:3.1 mixture of $2^{\circ}$ (2 diastereoisomers)$3^{\circ}$ (single diastereoisomer) sulfonamides 18, respectively, in spite of the $4: 1$ statistical preference for insertion at the methylene $\mathrm{C}-\mathrm{H}$ bonds in this molecule, indicating again the preferential amination of the more accessible equatorially oriented methine $\mathrm{C}-\mathrm{H}$. We next studied the regioselectivity of the reaction in isobutylbenzene and 1-ethyl-4-methylbenzene (Scheme 3). The observed reactivity ratio for amination at benzylic vs. tertiary alkylic and at primary $v s$. secondary benzylic $\mathrm{C}-\mathrm{H}$ bonds were, respectively, $2: 1$ and 4.2:1 (statistically corrected), which follow the trend of their expected relative $\mathrm{C}-\mathrm{H}$ bond dissociation energies $\left[\mathrm{BDE}\left(\mathrm{Me}_{3} \mathrm{C}-\mathrm{H}\right)=\right.$ $96.5 \mathrm{kcal} \mathrm{mol}^{-1} ; \quad \operatorname{BDE}\left(\mathrm{PhCH}_{2}-\mathrm{H}\right)=89.8 \mathrm{kcal} \mathrm{mol}^{-1}$; $\left.\operatorname{BDE}(\mathrm{PhCH}(\mathrm{Me})-\mathrm{H})=85.4 \mathrm{kcal} \mathrm{mol}^{-1}\right]^{20}$

A modest primary kinetic isotope effect $\left(\mathrm{KIE}, k_{\mathrm{H}} / k_{\mathrm{D}}=2.47\right.$ at $90{ }^{\circ} \mathrm{C}$; see $\mathrm{ESI} \dagger$ ) was measured for methylene $\mathrm{C}-\mathrm{H}$ bond amination in a competition reaction using a $1: 1$ mixture of cyclohexane and cyclohexane- $d_{12}$ and a limiting amount of $\mathrm{NfN}_{3}$. This value is considerably lower than those previously reported for reactions proceeding via a triplet nitrene $\mathrm{C}-\mathrm{H}$ abstraction/radical rebound amination mechanism $\left(k_{\mathrm{H}} / k_{\mathrm{D}}>5-6\right),{ }^{1 a, 4 a}$ but it is in the same range as those evaluated for analogous rhodium-catalyzed $\mathrm{C}-\mathrm{H}$ aminations $(\mathrm{KIE}=1.2-2.6)^{1 d}$ proposed to proceed via concerted asynchronous singlet nitrene insertion. In line with this observation is that the tertiary sulfonamides $17 \mathrm{c}$ and $18 \mathrm{c}$ were diastereoisomerically different (see ESI $\dagger)^{14 d}$ suggesting that the amination took place with retention of configuration, which can rule out a radical stepwise mechanism. Based on these results, a concerted asynchronous pathway can be reasonably proposed for the present nitrene $\mathrm{C}-\mathrm{H}$ insertion with only partial $\mathrm{C}-\mathrm{H}$ bond breaking in the transition state.

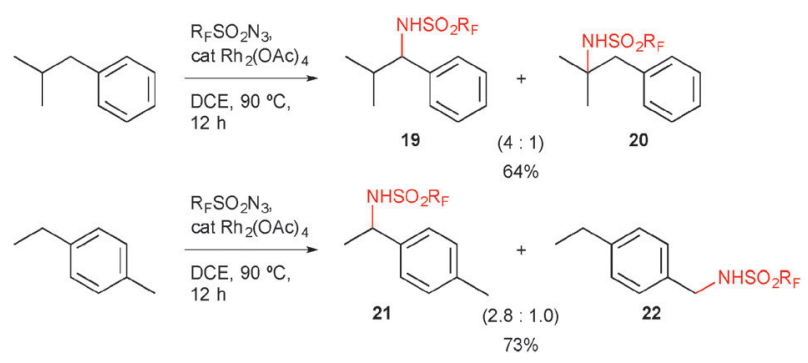

Scheme 3 Competitive benzylic vs. tertiary alkylic and primary vs. secondary $\mathrm{C}-\mathrm{H}$ bond amination. 


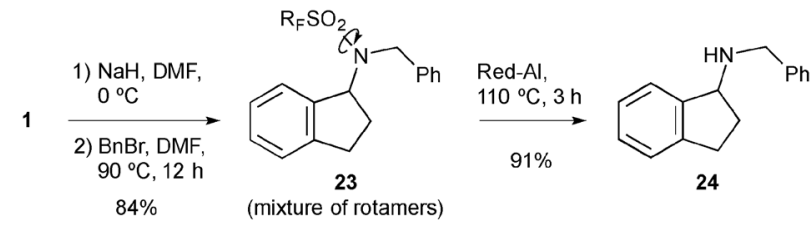

Scheme $4 \mathrm{~N}$-alkylation/reductive deprotection of sulfonamides.

The sulfonamide products could be further transformed taking advantage of the known reactivity of polyfluoroalkanesulfonamides. ${ }^{21}$ Thus, N-alkylation could be readily performed by reaction of the sulfonamide anion with an alkyl halide (Scheme 4). The resultant $N, N$-disubstituted nonafluorobutanesulfonamide showed restricted rotation around the $\mathrm{S}-\mathrm{N}$ bond, which caused a considerable broadening of the ${ }^{1} \mathrm{H}$ NMR signals at room temperature. ${ }^{22}$ Subsequent treatment with Red-Al in toluene under thermal conditions afforded the corresponding $\mathrm{N}$-alkylated amine in very good yield. This efficient two-step process can allow simple access to a variety of secondary amines, thus widely expanding the synthetic potential of the present $\mathrm{C}-\mathrm{H}$ bond amination approach.

In summary, we have reported a new intermolecular $\mathrm{C}\left(\mathrm{sp}^{3}\right)-\mathrm{H}$ amination of simple hydrocarbons using the shelf-stable nonafluorobutanesulfonyl azide in the presence of a dirhodium(II) tetracarboxylate catalyst. The amination products were obtained in moderate to good yields and could be further transformed to secondary amines via a simple two-step process. Possible mechanistic pathways for the amination process were briefly discussed on the basis of control experiments.

We gratefully acknowledge support by the Spanish Ministerio de Ciencia e Innovación (project MAT2010-20646-C04-03), the European Social Fund and Comunidad de Madrid (project S2009/PPQ-1634 "AVANCAT"), and CSIC for a JAEDOC contract to J.R.S. Thanks are due also to Prof. Jesús Sanz (IQOG-CSIC) for his valuable assistance with the KIE experiments.

\section{Notes and references}

1 (a) F. Collet, R. H. Dodd and P. Dauban, Chem. Commun., 2009, 5061-5074; (b) T. G. Driver, Org. Biomol. Chem., 2010, 8, 3831-3846; (c) R. T. Gephart and T. H. Warren, Organometallics, 2012, 31, 7728-7752; (d) J. L. Roizen, M. E. Harvey and J. Du Bois, Acc. Chem. Res., 2012, 45, 911-922.

2 (a) R. Breslow and S. H. Gellman, J. Chem. Soc., Chem. Commun., 1982, 1400-1401; (b) J.-L. Liang, J.-S. Huang, X.-Q. Yu, N. Zhu and C.-M. Che, Chem.-Eur. J., 2002, 8, 1563-1572; (c) S. Liang and M. P. Jensen, Organometallics, 2012, 31, 8055-8058.

3 (a) R. Breslow and S. H. Gellman, J. Am. Chem. Soc., 1983, 105, 6728-6729; (b) Z. Wang, Y. Zhang, H. Fu, Y. Jiang and Y. Zhao, Org. Lett., 2008, 10, 1863-1866; (c) Y. Liu and C.-M. Che, Chem.-Eur. J., 2010, 16, 10494-10501; (d) L. Liang, H. Lv, Y. Yu, P. Wang and J.-L. Zhang, Dalton Trans., 2012, 41, 1457-1460; (e) S. M. Paradine and M. C. White, J. Am. Chem. Soc., 2012, 134, 2036-2039; $(f)$ E. T. Hennessy and T. A. Betley, Science, 2013, 340, 591-595.

4 (a) S. K.-Y. Leung, W.-M. Tsui, J.-S. Huang, C.-M. Che, J.-L. Liang and N. Zhu, J. Am. Chem. Soc., 2005, 127, 16629-16640; (b) Y. Nishioka, T. Uchida and T. Katsuki, Angew. Chem., Int. Ed., 2013, 52, 1739-1742.

5 (a) J. D. Harden, J. V. Ruppel, G.-Y. Gao and X. P. Zhang, Chem. Commun., 2007, 4644-4646; (b) H. Lu, H. Jiang, L. Wojtas and X. P. Zhang, Angew. Chem., Int. Ed., 2010, 49, 10192-10196; (c) Y.-H. Ye, J. Zhang, G. Wang, S.-Y. Chen and X.-Q. Yu, Tetrahedron, 2011, 67, 4649-4654.

6 (a) I. Nägeli, C. Baud, G. Bernardinelli, Y. Jacquier, M. Moraon and P. Müllet, Helv. Chim. Acta, 1997, 80, 1087-1105; (b) C. G. Espino and J. Du Bois, Angew. Chem., Int. Ed., 2001, 40, 598-600; (c) C. G. Espino, K. W. Fiori, M. Kim and J. Du Bois, J. Am. Chem. Soc., 2004, 126, 15378-15379; (d) R. P. Reddy and H. M. L. Davies, Org. Lett., 2006, 8,
5013-5016; (e) K. W. Fiori and J. Du Bois, J. Am. Chem. Soc., 2007, 129, 562-568; $(f)$ C. Liang, F. Collet, F. Robert-Peillard, P. Müller, R. H. Dodd and P. Dauban, J. Am. Chem. Soc., 2007, 130, 343-350; $(g)$ K. Huard and H. Lebel, Chem.-Eur. J., 2008, 14, 6222-6230; (h) C. Lescot, B. Darses, F. Collet, P. Retailleau and P. Dauban, J. Org. Chem., 2012, 77, 7232-7240; (i) Q. Nguyen, K. Sun and T. G. Driver, J. Am. Chem. Soc., 2012, 134, 7262-7265; $(j)$ A. Nörder, S. A. Warren, E. Herdtweck, S. M. Huber and T. Bach, J. Am. Chem. Soc., 2012, 134, 13524-13531.

7 M. Ichinose, H. Suematsu, Y. Yasutomi, Y. Nishioka, T. Uchida and T. Katsuki, Angew. Chem., Int. Ed., 2011, 50, 9884-9887.

8 (a) G. He, Y. Zhao, S. Zhang, C. Lu and G. Chen, J. Am. Chem. Soc., 2011, 134, 3-6; (b) E. T. Nadres and O. Daugulis, J. Am. Chem. Soc., 2011, 134, 7-10.

9 (a) M. M. Díaz-Requejo, T. R. Belderraín, M. C. Nicasio, S. Trofimenko and P. J. Pérez, J. Am. Chem. Soc., 2003, 125, 12078-12079; (b) M. R. Fructos, S. Trofimenko, M. M. Díaz-Requejo and P. J. Pérez, J. Am. Chem. Soc., 2006, 128, 11784-11791; (c) Y. M. Badiei, A. Dinescu, X. Dai, R. M. Palomino, F. W. Heinemann, T. R. Cundari and T. H. Warren, Angew. Chem., Int. Ed., 2008, 47, 9961-9964; (d) D. A. Powell and H. Fan, J. Org. Chem., 2010, 75, 2726-2729; (e) R. T. Gephart, D. L. Huang, M. J. B. Aguila, G. Schmidt, A. Shahu and T. H. Warren, Angew. Chem., Int. Ed., 2012, 51, 6488-6492; $(f)$ Q. Michaudel, D. Thevenet and P. S. Baran, J. Am. Chem. Soc., 2012, 134, 2547-2550; (g) Z. Ni, Q. Zhang, T. Xiong, Y. Zheng, Y. Li, H. Zhang, J. Zhang and Q. Liu, Angew. Chem., Int. Ed., 2012, 51, 1244-1247.

10 (a) B. P. Gómez-Emeterio, J. Urbano, M. M. Díaz-Requejo and P. J. Pérez, Organometallics, 2008, 27, 4126-4130; (b) Á. Beltrán, C. Lescot, M. M. Díaz-Requejo, P. J. Pérez and P. Dauban, Tetrahedron, 2013, 69, 4488-4492.

11 (a) Z. Li, D. A. Capretto, R. O. Rahaman and C. He, J. Am. Chem. Soc., 2007, 129, 12058-12059; (b) Y. Zhang, B. Feng and C. Zhu, Org. Biomol. Chem., 2012, 10, 9137-9141.

12 B. Kalita, A. A. Lamar and K. M. Nicholas, Chem. Commun., 2008, 4291-4293.

13 For pioneering work, see: (a) D. S. Breslow, M. F. Sloan, N. R. Newburg and W. B. Renfrow, J. Am. Chem. Soc., 1969, 91, 2273-2279; (b) T. Shingaki, M. Inagaki, N. Torimoto and M. Takebayashi, Chem. Lett., 1972, 1181-1184; (c) D. S. Breslow, E. I. Edwards, E. C. Linsay and H. Omura, J. Am. Chem. Soc., 1976, 98, 4268-4275; (d) N. Torimoto, T. Shingaki and T. Nagai, J. Org. Chem., 1978, 43, 631-633; (e) S.-Z. Zhu, J. Chem. Soc., Perkin Trans. 1, 1994, 2077-2081.

14 (a) H. F. Bettinger, M. Filthaus, H. Bornemann and I. M. Oppel, Angew. Chem., Int. Ed., 2008, 47, 4744-4747; (b) A. A. Lamar and K. M. Nicholas, J. Org. Chem., 2010, 75, 7644-7650; (c) H. J. Kim, J. Kim, S. H. Cho and S. Chang, J. Am. Chem. Soc., 2011, 133, 16382-16385; (d) M. Ochiai, K. Miyamoto, T. Kaneaki, S. Hayashi and W. Nakanishi, Science, 2011, 332, 448-451; (e) Q. Xue, J. Xie, H. Li, Y. Cheng and C. Zhu, Chem. Commun., 2013, 49, 3700-3702.

15 (a) N. Kamigata, K. Yamamoto, O. Kawakita, K. Hikita, H. Matsuyama, M. Yoshida and M. Kobayashi, Bull. Chem. Soc. Jpn., 1984, 57, 3601-3602; (b) L. Benati, D. Nanni and P. Spagnolo, J. Org. Chem., 1999, 64, 5132-5138.

16 B. A. Shainyan and L. L. Tolstikova, Chem. Rev., 2013, 113, 699-733. 17 (a) S. Yekta, V. Prisyazhnyuk and H.-U. Reissig, Synlett, 2007, 2069-2072; (b) J. R. Suárez, B. Trastoy, M. E. Pérez-Ojeda, R. Marin-Barrios and J. L. Chiara, Adv. Synth. Catal., 2010, 352, 2515-2520; (c) B. Trastoy, M. E. Pérez-Ojeda, R. Sastre and J. L. Chiara, Chem.-Eur. J., 2010, 16, 3833-3841; (d) J. L. Chiara and J. R. Suárez, Adv. Synth. Catal., 2011, 353, 575-579; (e) J. Gu, W. Xiong, Z. Zhang and S. Zhu, Synthesis, 2011, 1717-1722; $(f)$ J. R. Suárez, J. Kwiczak, K. Grenda, M. L. Jimeno and J. L. Chiara, Adv. Synth. Catal., 2013, 355, 913-918.

18 (a) W. Xiong, Y. Xin, J. Han and S. Zhu, J. Fluorine Chem., 2010, 131, 867-872; (b) W. Xiong, Y. Xin, J. Zhao and S. Zhu, Synthesis, 2011, 1142-1148; (c) W. Xiong, H. Zhang, Y. Xin and S. Zhu, Tetrahedron, 2011, 67, 2232-2237; (d) W.-t. Xiong, J.-w. Zhao, J.-w. Gu and S. Zhu, Tetrahedron, 2011, 67, 5235-5243.

19 S. Zhu and P. He, Tetrahedron, 2005, 61, 5679-5685.

20 (a) D. F. McMillen and D. M. Golden, Annu. Rev. Phys. Chem., 1982, 33, 493-532; (b) S. J. Blanksby and G. B. Ellison, Acc. Chem. Res., 2003, 36, 255-263.

21 (a) J. B. Hendrickson, R. Bergeron and D. D. Sternbach, Tetrahedron, 1975, 31, 2517-2521; (b) K. Miyamoto, M. M. Hoque and S. Ogasa, J. Org. Chem., 2012, 77, 8317-8320.

22 I. M. Lyapkalo, H.-U. Reissig, A. Schäfer and A. Wagner, Helv. Chim. Acta, 2002, 85, 4206-4215. 